\title{
DIGITAL DOCUMENTATION AND ARCHIVING LOW COST: LA HABANA VIEJA IN CUBA
}

\author{
C. Morganti ${ }^{a}$, C. Bartolomei ${ }^{a}$ * \\ a Department of Architecture, Alma Mater Studiorum University of Bologna, Bologna, Italy - \\ (caterina.morganti4, cristiana.bartolomei)@unibo.it
}

\section{Commission II}

KEY WORDS: Augmented Reality, Cuba, Cultural Heritage, Low-cost system, La Habana, Photo-modelling,

\begin{abstract}
:
This article deepens the subject of photo-modelling applied to architecture, on a medium and large scale and it shows all the possibilities to apply the last technologies of augmented reality and virtual reality to the historical and architectural contest of Havana City in Cuba. The context was quite unsuitable to our project because of different and complex reasons. The need to minimize the size of the tools, their weight and cost. Minimize the time of survey and photographic shot on site. To face the difficulties given by the continuing presence of a chaotic influx of people disturbing the work. Not least the difficulty of having a limited number of daily hours available to carry out photographic shots that requires special lighting conditions. This article describes the necessary steps to obtain a 3D dimensional textured model from reality through a photographic set.
\end{abstract}

\section{INTRODUCTION}

The historical research and analysis and the knowledge of the state of art identify the methods used for the survey and the 2D and 3D graphic rendition of the buildings that surround the five main squares of the Habana Vieja. A very interesting topic for the Oficina del Historiador de Ciudad de la Habana, a Cuban public body, that oversees the architectural and cultural heritage of the city. The Oficina was established in 1938 to protect the old Havana. The restoration of the historic area was developed by Dr. Eusebio Leal Spengler, who was elected as the Historiador de la Ciudad de La Habana in 1967 and is currently the highest authority for the complete restoration of the historic centre. Such historic centre was declared a World Heritage Site by UNESCO in 1982. The Oficina is the engine of many initiatives taking place in Havana. It could be called Sovereignty, with the aim of safeguarding the national identity through the research, the promotion and the development of culture.

The main aim of the study is the survey and the graphic rendition of the five squares that are part of the Old Town Centre of Old Havana: Plaza de Armas, Plaza Vieja, Plaza de San Francisco, Plaza de la Catedral, and Plaza del Cristo (Figure 1). The survey was developed with traditional direct methods and a photographic campaign. The graphic rendition was carried out with digital tools and proper software both from computer graphics and computer vision. Photo-modelling was the main technique used for the rendition of scale 3D models, both for scale building and scale urban as well.

Surveys on a medium and large scale of parts of cities generate a considerable amount of data and information that are supposed to be processed at a later time and usually in faraway places from where the survey was carried out. Our study in actual fact lays thousands of miles overseas from Cuba.

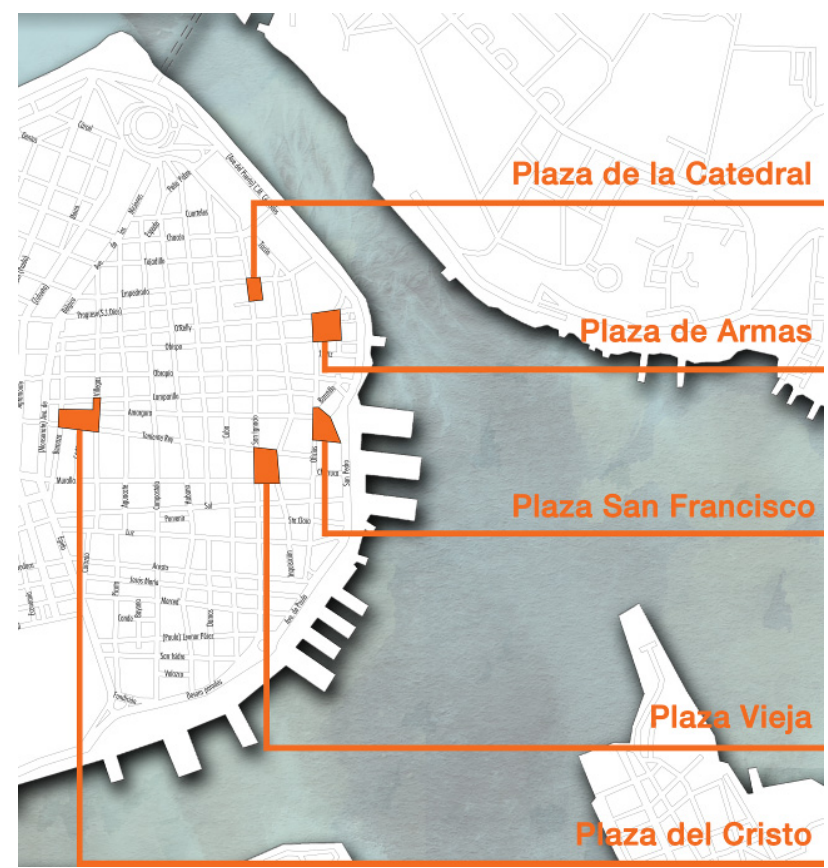

Figure 1. Plan of Habana Vieja

The survey was carried out according to an accurate work program. A precise tool selection was made and data was saved with particular attention. For this last operation, the laptop memory and an external hard disk were used, so that there were at least three supports, including the SD card.

The tools that were used for the survey and the photographic campaign were chosen for their practicality, effectiveness, size, weight and cost. They are the ones shown in Figure 2.

* Corresponding author 


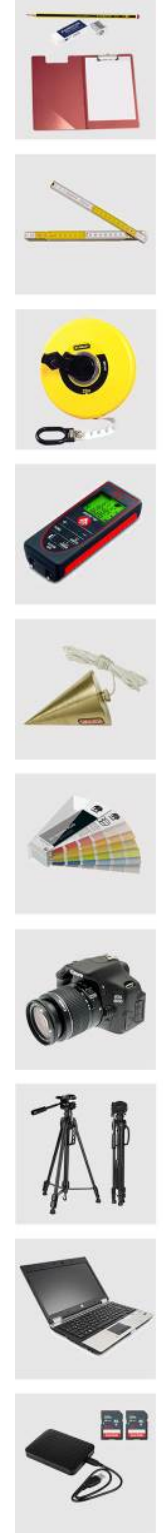

drawing tools

wooden folding

measuring

laser distance

plumb line

paint swatches

reflex digital

camera EOS 600D

camera tripod

laptop

external hard disk drive -

SD memory card

Figure 2. Tools used for the survey

The study of the survey needed to take a look at the places for checking which parts of the day had the best light to take the most proper photos. That is why a scouring of the interested sites was carried out at various hours of the day. The results were that the strong shadows disturbed the shot quality and the most suitable hours resulted to be the early morning and the late afternoon ones. They are public places, so it was also estimated the influx of people that complicated the cleaning of the photographic shot (Figure 3). At first the photo-modelling technique seems a simple and automatic method. It yields from a photographic set a 3D dimensional, textured, complete and scale model. Unfortunately this is not the case, although photomodelling is a method with a high degree of automation, which greatly simplifies the generative process of the $3 \mathrm{D}$ model. The whole process needed to be supported by a deep critical interpretation, especially in the shot taking phase, which required the individualization of the architectural shapes of the surveyed squares. As mentioned previously, a Canon EOS $600 \mathrm{D}$ reflex digital camera was used with a standard zoom lens EF-S 18-55 IS II. We took photos at the maximum resolution camera of 18 megapixels. The JPEG format was the format used for the images. It is actually the most used format for commercial photo devices to compress the digital image with continuous tone both in grey and in colour. Even if the majority producers of modelling software recommend the RAW format as a method of data storing which shows an image with less recording quality loss.
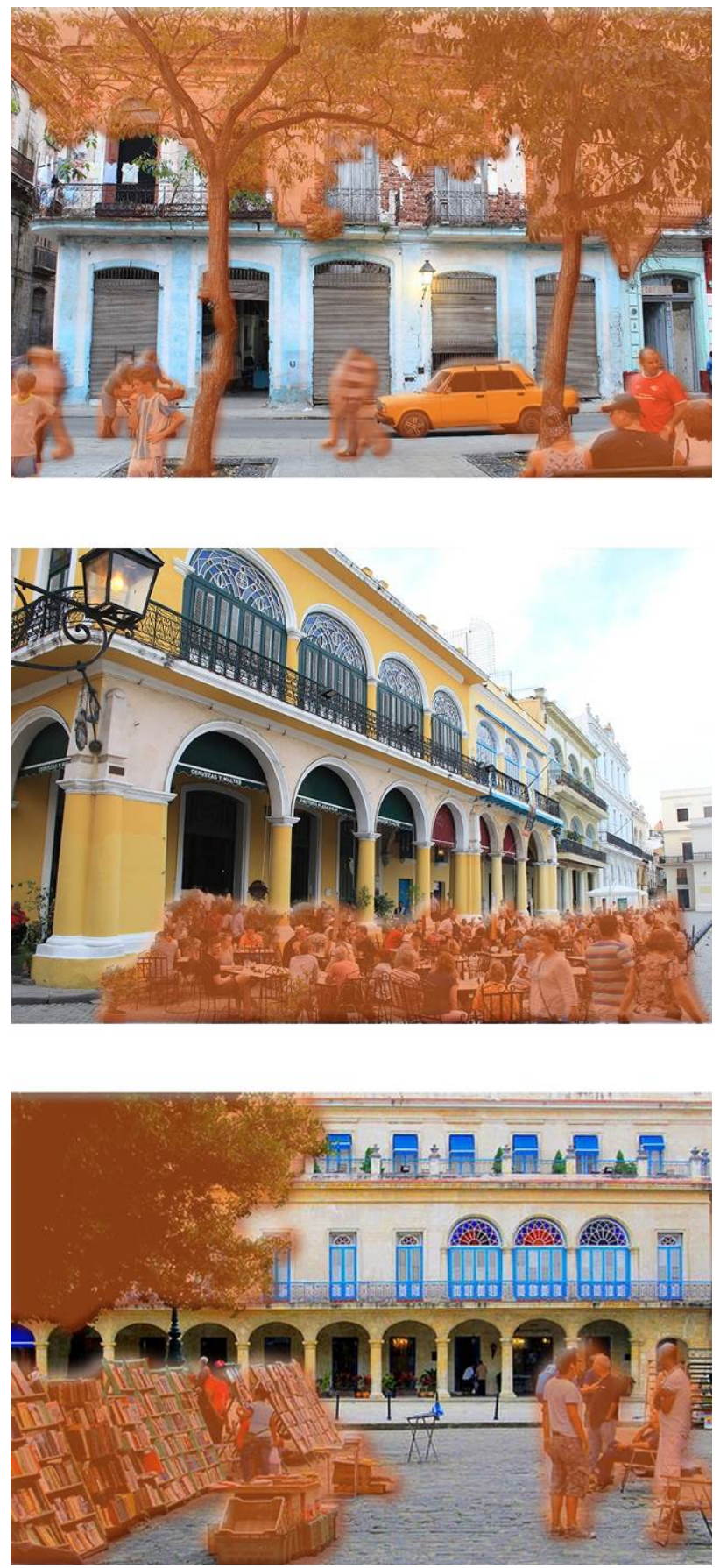

Figure 3. Photographic interferences

Most of the photographs were taken with the help of a tripod to get the sharpest images and a $18 \mathrm{~mm}$ focal length. Once we decided on the settings for the camera, then we started with the shot taking using the methods analysed in advance in our study. These methods follow the case-by-case rules, that are not always possible to be respected because of objective physical impediments to our view of the five photographed squares. Some of these impediments are common like fixed or mobile 
obstacles as vegetation, urban furnishing, and temporary installations as stages and walking markets, vehicles, people, and auto-occlusions yielded by their own particular shapes (like balconies, porches and other front elements). It was necessary a proper ability to photograph the entire fronts of the buildings, avoiding all those physical impediments.

We classified the five squares according to their era of construction and according to their main aesthetic characteristics: surface, perimeter and number of buildings. Each square has its own particular elements that determined the survey and conditioned the freedom of movement to choice the right shot taking and to avoid the obstacle present.

The photographic shot of each square includes in all: fronts of the buildings and their porches, pavements, monuments and fountains. Different techniques were used in relation to the type of rendition of each different element and to the achievement of analyses and representations. There are three techniques that are used in a combined or integrated way, that are: parallel or multiple axes shot, convergent axis shot, and panoramic shot (cylindrical, spherical or partial). Each group of taken images was then associated with the measurements of some reference sizes in the three dimensions (widths, heights, depths), that are necessary to scale the model and to control the correctness of the graphic rendition. The measurements were previously carried out in excess by using traditional measuring tools like: metric tape, rigid meter and laser meter. When the surveys were completed, it was then important to identify the colorimetry of the paintings of the fronts like plaster and woodwork. Even in this case we proceeded with the use of a very simple, quick and effective tool: the bunch of colours. This direct method allowed to detect the colours with a very low error rate, unlike the colours taken with the camera, that are susceptible to so many interferences (Figure 4, Figure 5 and Figure 6).

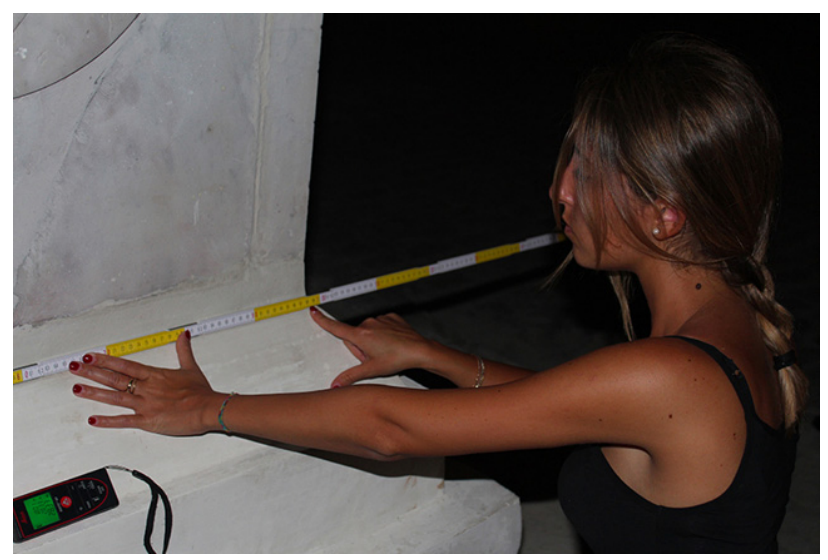

Figure 4. Metric survey

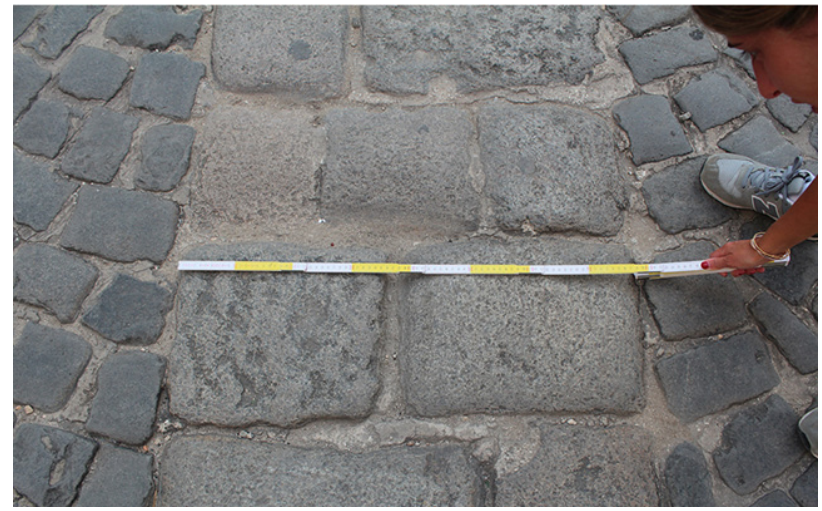

Figure 5. Metric survey

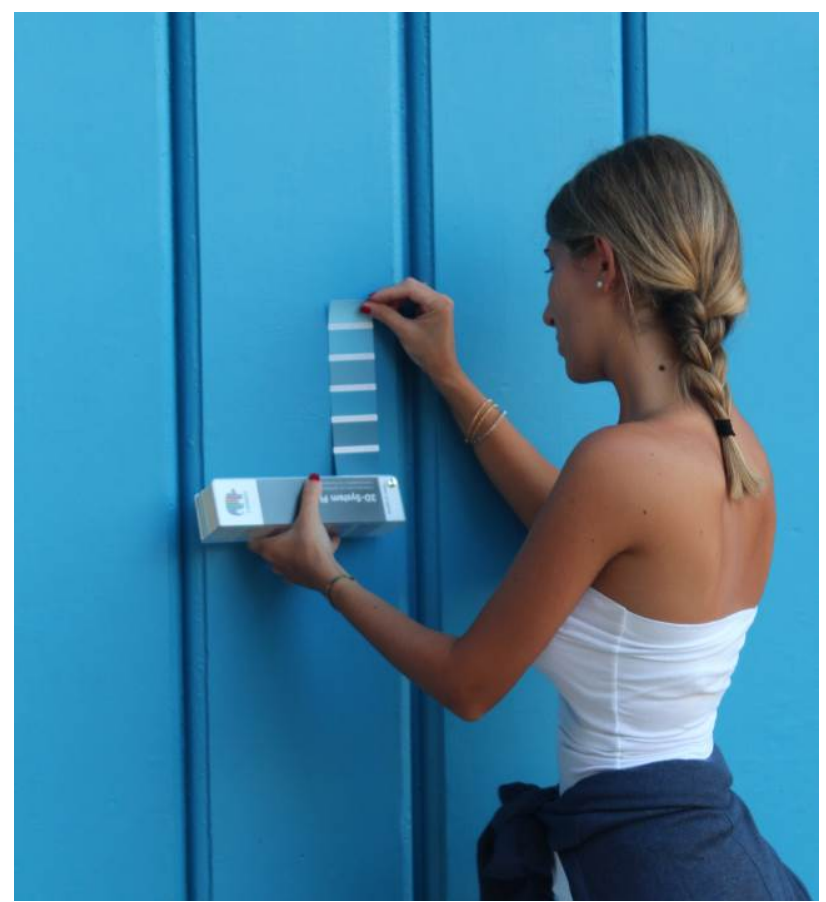

Figure 6. Colorimetric survey

The error of the model was calculated according to the metric quality and the precision of the result of the data processing with a proper software. It was not important the kind of photographic technique used (convergent, parallel or cylindrical). This calculation took into account the intrinsic errors of the measuring device: camera resolution; a not clear selection in matching points; the correction at cameras calibration and orientation. The scale of the error expressed in pixels corresponds to the error expressed in $\mathrm{cm}$ according to the following proportion (1) (Figure 7):

error $(\mathrm{cm})=$ error $($ pixel $) \times$ real distance $(\mathrm{cm}) /$

image distance (pixel)

For example. If we measure with a metric tape a front with a real horizontal length of $1748 \mathrm{~cm}$, the error can be estimated in (2):

error $(6$ pixels) $\mathrm{x}$ real distance $(3223 \mathrm{~cm}) /$

image distance $(4435$ pixels $)=4,36 \mathrm{~cm}$ (error)

Added up to the error of model measuring is the measurement error inherent in the survey. This can amount to as much as 10 $\mathrm{mm}$ to every $2000 \mathrm{~cm}$.

For which at $3223 \mathrm{~cm}$ of the facade we have (3):

real distance $(3223 \mathrm{~cm}) \times 1 \mathrm{~cm} / 2000 \mathrm{~cm}=1.61 \mathrm{~cm}$

(survey measurement error)

Hence the absolute error amounts to $5,97 \mathrm{~cm}$.

Expressed in percentage the absolute error corresponds to $0.185 \%$.
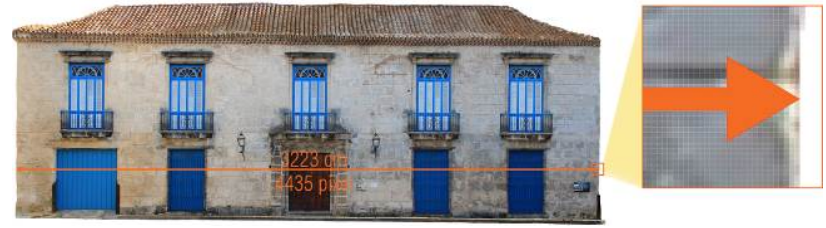

Figure 7. Example of linear error 
After the survey and the photographic campaign, we proceeded with the data processing through a personal computer with quite good hardware performances. So that if there are many photos it is able to limit the time of loading:

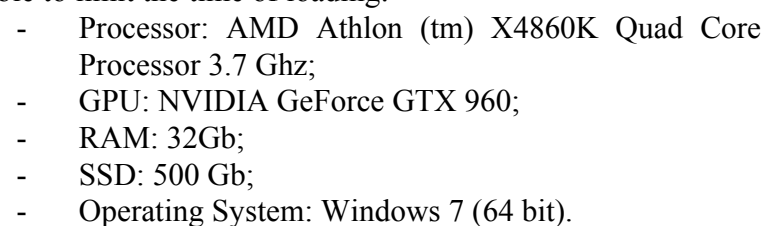

There are various processing programs available on the market about the photo-rectifier, about the photo-modelling and 2D and $3 \mathrm{D}$ graphics. The following software was selected for the realization of this study:

Perspective Rectifier (2D photo rectifier);

- Agisoft PhotoScan Professional (for 3D photomodelling);

AutoCAD Autodesk (for graphic re-processing).

Once the three dimensional model has been created by Agisoft PhotoScan, it was possible to extract therefrom some orthophotos, i.e. view reproductions parallel to the main plane of the object surveyed.

The orthophoto projection is an image of the artifact often used to represent in bi dimensional perspective highly complex architectonic elements like vaults, cupolas, baroque churches like in the case of the Havana cathedral. The making of an orthophoto consists in fitting radiometric information of the image into the framework of the orthogonal view of a three dimensional model. In other words, in order to obtain an orthophoto, we must have a three dimensional model at our disposal. In the professional jargon, it is said that it is possible to make an orthophoto if one has an oriented DEM (Digital Elevation Model). In contrast to image rectification, an orthophoto is actually an orthogonal projection without the elements which do not fall on planes parallel to the view. In order to translate a perspective into a technical drawing in .dwg format raster images of the orthophoto have then been imported within the AutoCAD software and we proceeded to retrace the essential (salient) lines thus obtaining a vectorial technical drawing of good precision. Even from a single photographic image it is possible to obtain a 'photomap', an elaboration useful for metric documentation of extensive flat surfaces like façades, ceilings or floorings - by applying the principles of projective geometry. The procedure of obtaining a photomap is based on the elaboration and transformation of a photogram from the perspective projection into the orthographic one. In order that such a transformation were feasible, it is necessary to identify in space the position of at least five points which have to be observable both on the photogram and on the object surveyed: such points - indicated by proper markers or identified by natural points - are generally measured with topographic tools. Another condition for realizing a metrically correct photomap is rooted in the knowledge of the intrinsic parameters of the photo camera, data like the focal distance, the photogram dimension, the positioning of the main point, distortions generated by lenses, etc. Frequently enough the shot distance is not sufficient to include the whole architectonic element and then it is necessary to have recourse to the photomosaic obtained by juxtaposing a number of photomaps. In order to test the potential of the technique of orthophoto projection obtained by the application of Agisoft PhotoScan software in comparison with the photomap, while using the software Perspective Rectifier for the purpose of image rectification, a number of perspectives have been realized by applying both techniques. A comparison of the results obtained through both programs revealed differences demonstrated in the examples of the figures (Figure 8 and Figure 9) have been observed.
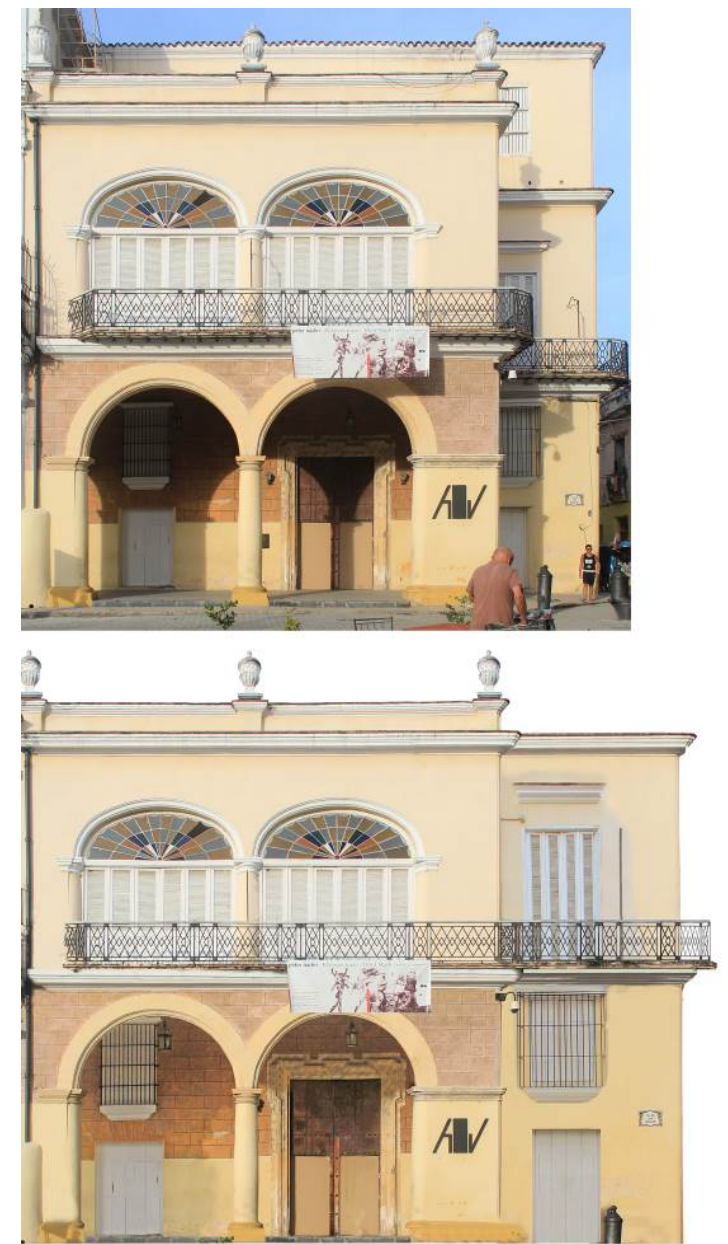

Figure 8. Comparison of photo rectification (A) with the orthophoto map (B) of a building in Plaza Vieja
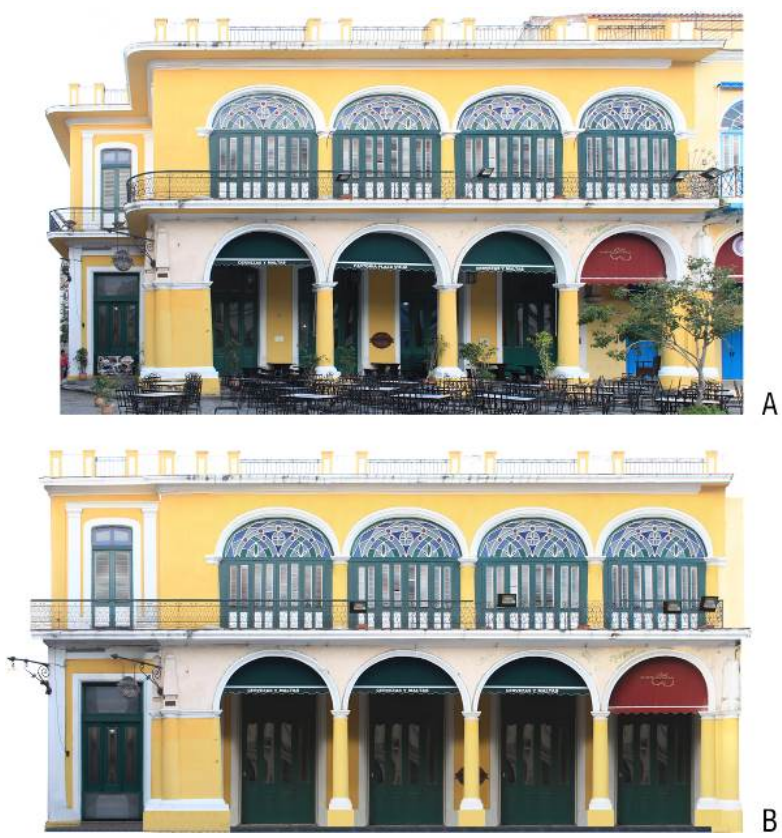

Figure 9. Comparison of the photo rectification (A) and the orthophoto map (B) of a building in Plaza Vieja 
The application of photo-modelling to complex cases on a medium and large scale such as those in question made possible to understand the potential of this surveying technique in the architectural and urban application. The fronts and arcades of 59 buildings, 2 fountains and 2 monuments belonging to the 5 squares of Havana's Old Town Centre were surveyed in a quite short time. In total there are about $30000 \mathrm{~m}^{2}$ of pavements and as many vertical surfaces of the fronts. The results are more than satisfactory. In fact we created photorealistic models that were able to provide a great number of geometric information, a characterization of the materials, of the textures and the colours of the surfaces of the buildings and the squares. We used traditional, commercial, low cost and easily transportable tools thanks to their light weight and their small size. It was possible to obtain an archival value and a utility for future research. The use of these models furthermore permits to produce 3D dimensional views, to produce animations, to explore through a display software and to acquire data, to create prospects and profiles (Figure 10, Figure 11 and Figure 12).
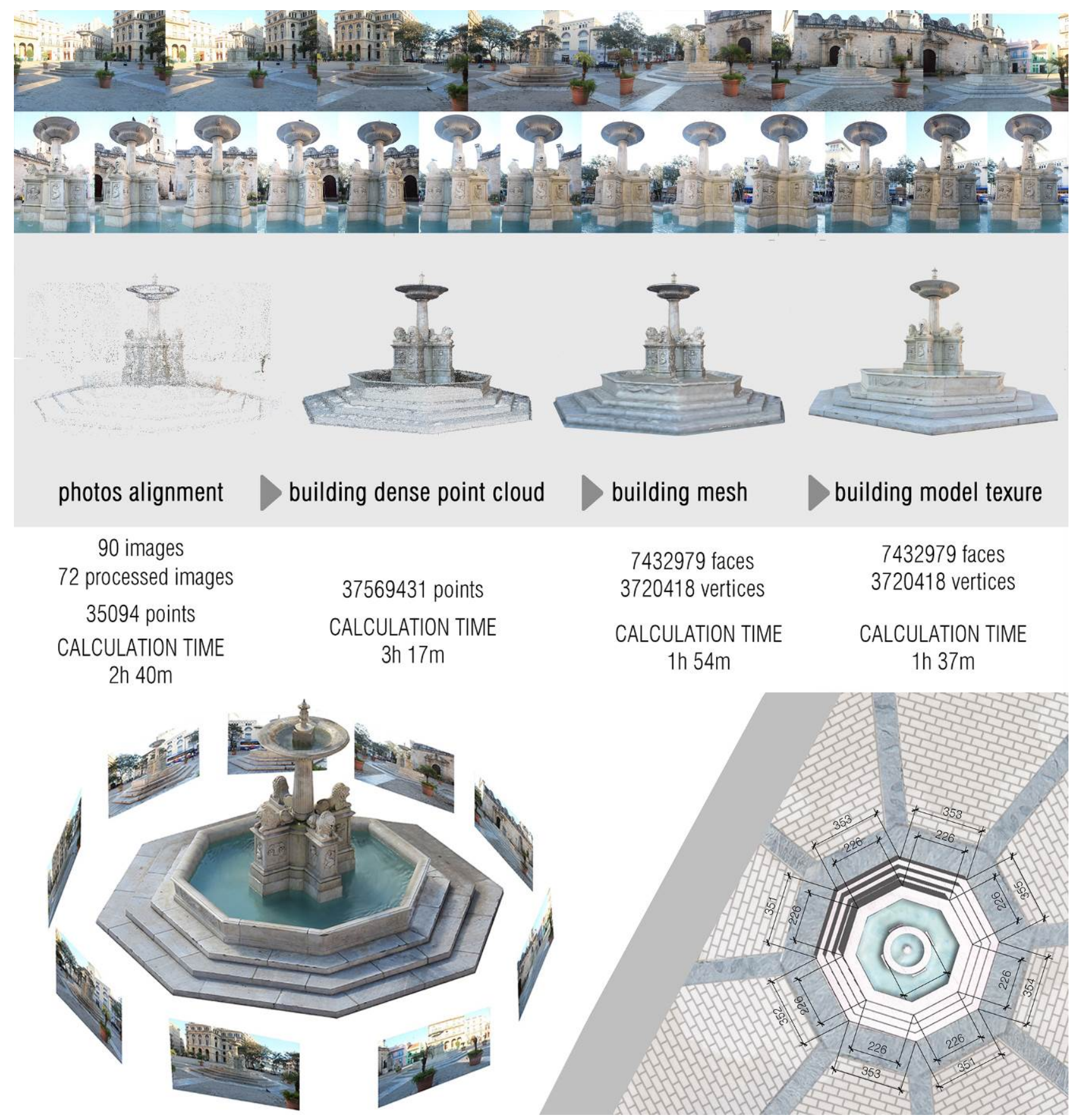

Figure 10. Application of photo-modelling (fountain in Plaza de San Francisco) 


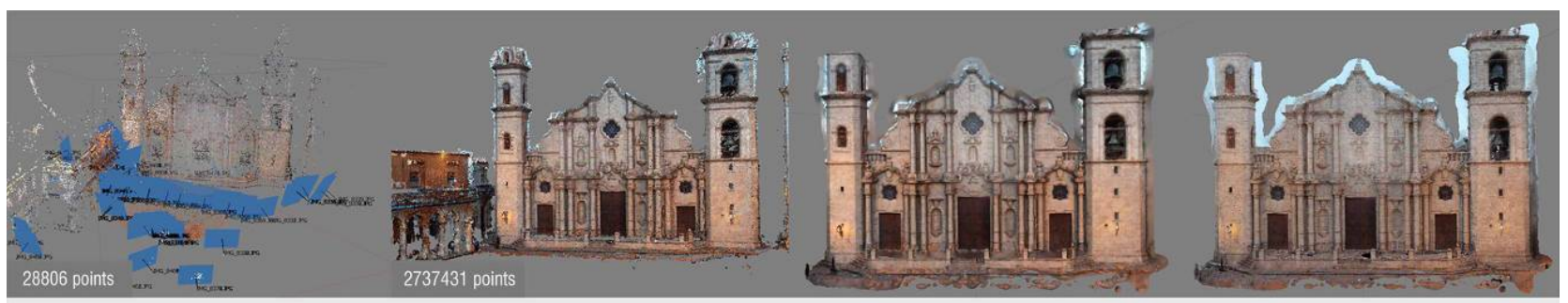

\section{photos alignment $>$ building dense point cloud $>$ building mesh $>$ building model texure}

IMAGES 105 images 2737431 points $\quad 533281$ faces 268537 vertices 533281 faces 268537 vertices

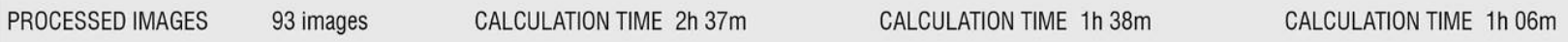
28806 points

CALCULATION TIME 2h 02m
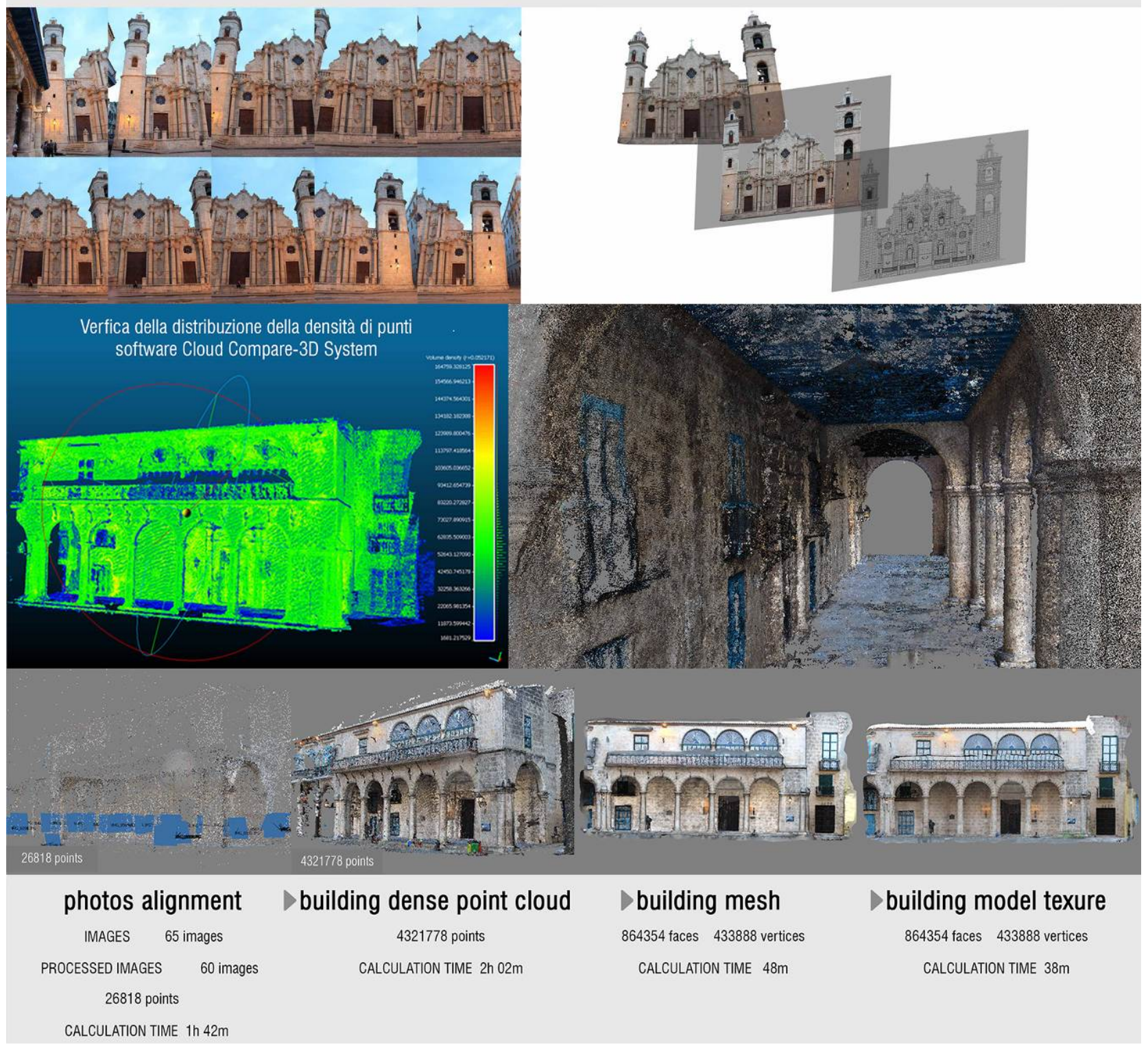

Figure 11. Application of photo-modelling (buildings in Plaza de la Catedral) 

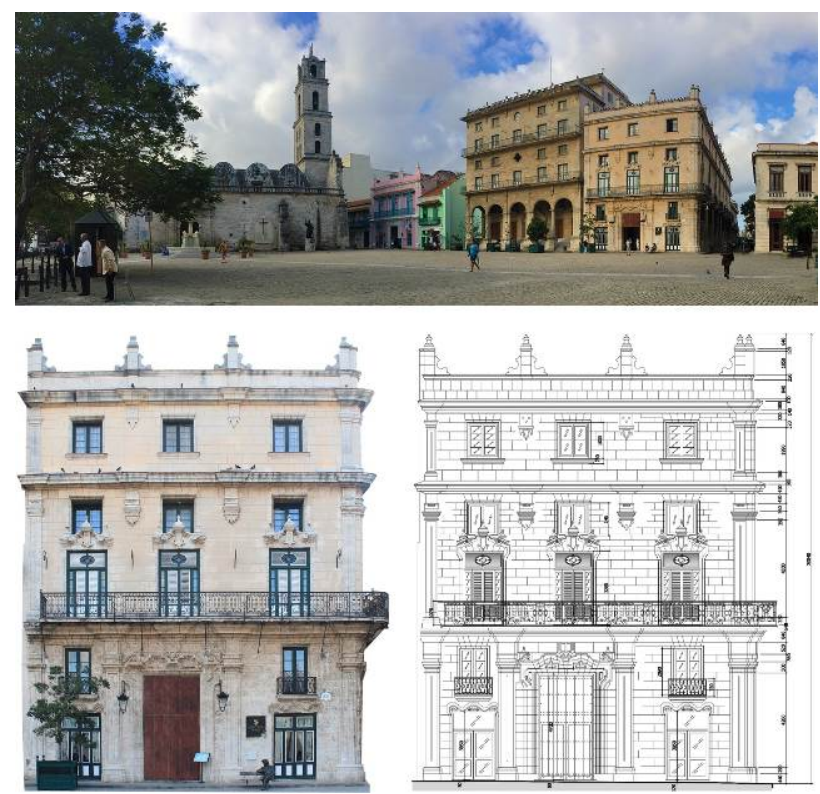

Figure 12. 2D photo plane creation (building in Plaza de San Francisco)

The study is also supposed to provide the useful material for the implementation of an application for portable devices (like smartphone and tablet) for popular, cultural and tourist purposes. This material can be used offline and online, and also as database to create immersive virtual reality applications (Fig. 13) and AR (Augmented Reality) applications (Figure 14 Figure 19).

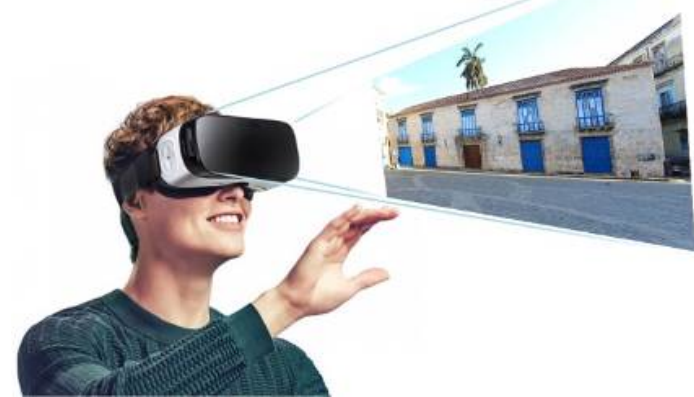

Figure 13. Example of an application of immersive virtual reality (Plaza de la Catedral)

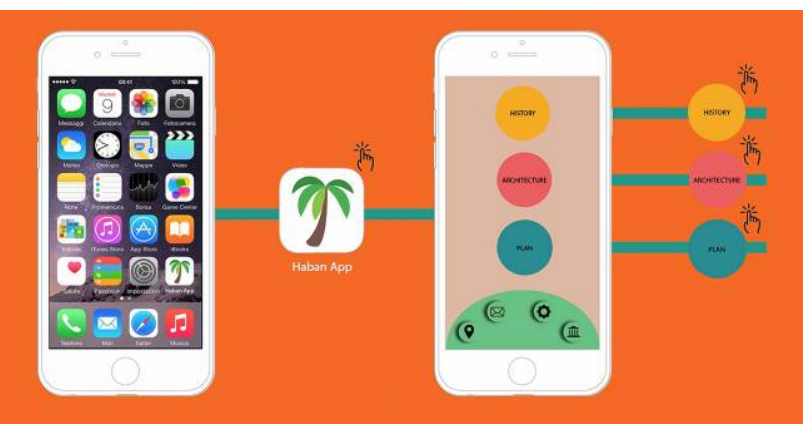

Figure 14. Example of a digital mockup

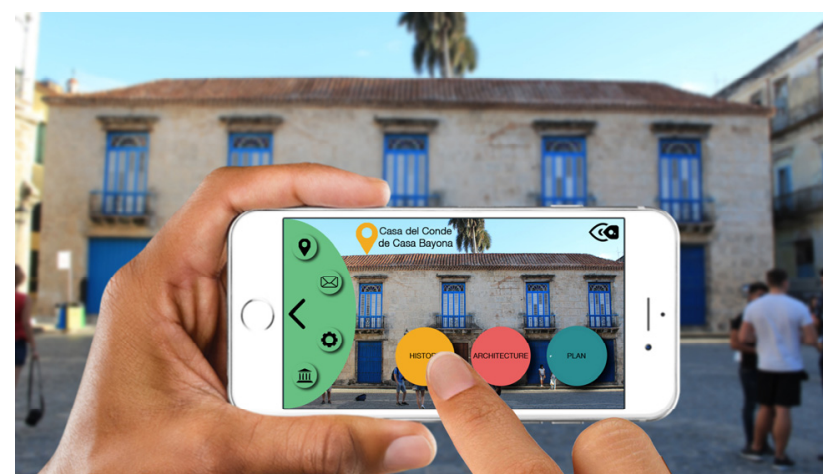

Figure 15. Example of an application of aumented reality (Plaza de la Catedral)

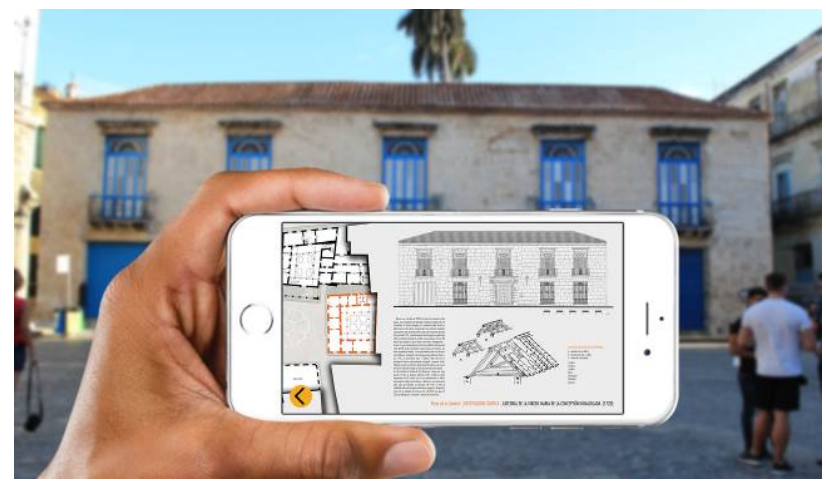

Figure 16. Example of an application of aumented reality (Plaza de la Catedral)

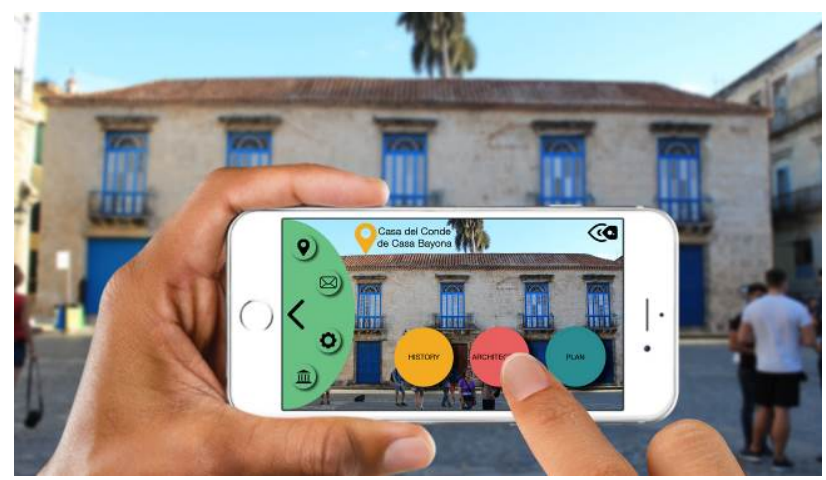

Figure 17. Example of an application of aumented reality (Plaza de la Catedral)

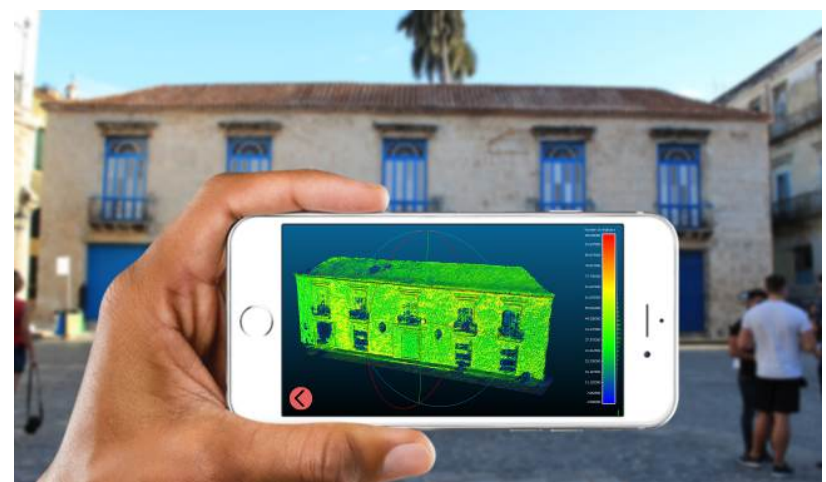

Figure 18. Example of an application of aumented reality (Plaza de la Catedral) 


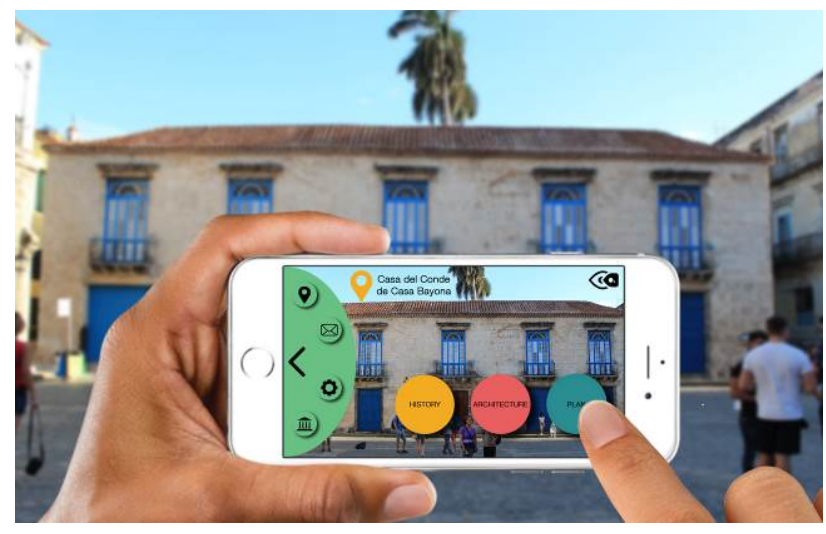

Figure 19. Example of an application of aumented reality (Plaza de la Catedral)

Our project shows the potentialities and criticalities we met, in order to search a procedural and methodological standard for survey and data collection and to develop an AR / VR application that can be used in the Cuban reality. The system analysed is usable by both tourist and citizen that have a common mobile device equipped with a GPS system. Internet has a very difficult connection in Cuba, so that it is necessary to provide a database containing all the useful information such as maps, tours, photographs, 2D and 3D images from the present and the past and easy to suit for the future, to be overlapped to live images. This material is absolute innovative for Cuba.

\section{REFERENCES}

AA.VV., 2011. La plaza Vieja de La Habana - proceso de recuperaciòn. ed. Consejerìa de Obras Pùblicas y Vivienda, Sevilla.

AA.VV., 2009. Regulaciones Urbanisticas Ciudad de La Habana - La Habana Vieja - Centro Historico. ed. Boloña, La Habana.

AA.VV., 2009. Manejo y gestiòn de centros històricos. ed. Boloña, La Habana.

AA.VV., 2015. Monumentos nacionales de la Repùblica de Cuba. ed. Collage Ediciones, La Habana.

AA.VV., 1998. Guì de arquitectura. ed. consejo editorial, La Habana.

Arduini, G., 2012. La realtà aumentata e nuove prospettive educative. "Education Sciences \& Society», 3, Ri-pensare la pedagogia, ri-pensare l'educazione.
Bedoya Pereda, F., 2008. La Habana desaparecida. ed. Boloña. La Habana.

Bonacini, E., 2011. Nuove tecnologie per la fruizione e la valorizzazione del patrimonio culturale. Aracne Editrice, Roma.

Butchart, B., 2011. Augmented Reality for Smartphones. A Guide for developers and content publishers, «TechWatch Report, JISC Observatory».

Clemente, P., 2009. La fotomodellazione applicata a differenti scale di rappresentazione. tesi di laurea, Venezia.

De las cuevas Toraya, J., 2001. 500 años de construcciones en Cuba. ed. Chavìn, La Habana.

De Luca, L., 2011. La fotomodellazione architettonica. Rilievo, modellazione, rappresentazione di edifici a partire da fotografie. ed. Dario Flaccovio, Palermo.

Foresi, L., 2008. La Fotomodellazione come strumento di comprensione dell'Architettura. tesi di laurea, Camerino.

Foschi, R., 2015. La fotomodellazione per il rilievo architettonico: metodologie, potenzialità e criticità. rivista ingenio n. 36, www.ingenio-web.it.

Garcia Santana, A., 2009. Urbanismo y arquitectura de la Habana Vieja - siglos XVI al XVIII, ed. Boloña, La Habana.

Marimon, D., Sarasua, C., Carrasco, P., Álvarez, R., Montesa, J., Adamek, T., Romero, I., Ortega, M. and Gascó, P., 2010. MobiAR: Tourist Experiences through Mobile Augmented Reality. NEM 2010, Networked and Electronic Media.

Niccolucci, F., 2005. Technologies for the public understanding of the past: EPOCH's contribution. ICHIM 05 - Digital Culture \& Heritage / Patrimoine \& Culture Numérique. (C) Archives \& Museum Informatics Europe, $16 \mathrm{p}$.

Venegas Fornias, C., 2003. Plazas de intramuro, ed. Mayra Fernàndez Peròn, La Habana.

Vlahakis, V., Karigiannis, J., Tsotros, M., Gounaris, M., Almeida, L., Stricker, D., Gleue T., Christou, I. T., Carlucci, R. and Ioannidis, N., 2001. ARCHEOGUIDE: First results of an Augmented Reality, Mobile Computing System in Cultural Heritage Sites. Virtual Reality, Archeology, and Cultural Heritage, 9.

Zoellner, M., Stricker, D., Bleser, G. and Pastarmov, Y., 2007. iTACITUS - Novel Interaction and Tracking Paradigms for Mobile AR. The European research network of excellence in open cultural heritage (EPOCH), pp. 110-117. 